\title{
Anatomical variations of hepatic artery using the multidetector computed tomography angiography
}

\author{
S.M. Zaki1,2, A.H.K. Abdelmaksoud², B.E.A. Khaled², ${ }^{2}$, I.A. Abdel Kader ${ }^{2}$ \\ ${ }^{1}$ Fakeeh College for Medical Sciences, Jeddah, Saudi Arabia \\ ${ }^{2}$ Faculty of Medicine, Cairo University, Cairo, Egypt \\ ${ }^{3}$ College of Medicine, Jouf University, Saudi Arabia \\ [Received: 2 July 2019; Accepted: 31 July 2019]
}

Background: The frequency of normal and aberrant hepatic arteries differs among ethnicities. The aim of our work was to study the frequency of normal and aberrant hepatic arteries among Egyptians using multidetector computed tomography (MDCT) and to compare our prevalence with the prevalence of other nationalities. In addition, the gender differences of such variations were clarified. Moreover, the arterial feeding of hepatic segment IV was determined.

Materials and methods: The present study was carried out on 500 patients (409 males and 91 females). Abdominal CT was performed using two MDCT systems, a 64-row, and a 256-slice system.

Results: According to Michel's classification, the normal anatomy (type I) was observed in 369 (73.8\%) cases, while anomalous hepatic arterial pattern was detected in 131 (26.2\%) cases. These anomalies were distributed as follows: type II in 36 (7.2\%) cases, type III in 60 (12\%) cases, types IV and V in 5 cases for each (1\% each), type VI in 14 (2.8\%) and types VIII and IX in a single case for each (0.2\% each). Neither type VII nor type $X$ was detected. Nine (1.8\%) unclassified cases were observed. According to Hiaat's classification, the anomalies were distributed as follows: type II in 41 (8.2\%) cases, type III in 74 (14.8\%) cases, type IV in 6 (1.2\%) cases, type $V$ in a single case (0.2\%) and type VI in $2(0.4 \%)$ cases. Finally, 7 (1.4\%) unclassified cases were observed. Common hepatic artery (CHA) originated from coeliac trunk in $98 \%$ (79.8\% males and $18.2 \%$ females). It originated from the abdominal aorta in $0.4 \%$ and from the superior mesenteric artery (SMA) in $0.4 \%$. It was absent in $1.2 \%$. Right hepatic artery (RHA) originated from the CHA in $86.6 \% 169.8 \%$ males and $16.8 \%$ females) and from the SMA in 13.2\% (11.8\% males and 1.4\% females) and from the abdominal aorta in $0.2 \%$ (a single male case). Left hepatic artery (LHA) originated from the CHA in $91.2 \%$ and from the left gastric artery $(L G A)$ in $8.8 \%$. The most common origin of the segment IV blood supply was the LHA in 60.8\%, followed by the RHA in 35\%. Less commonly, blood supply derived from the hepatic artery proper (HAP) in 1\%. Combined supply derived from RHA and LHA in 0.8\%, from the LHA and HAP in 2\% and the least encountered was from the RHA and HAP in $0.4 \%$. Conclusions: Hepatic artery variations among Egyptians have a different distribution when compared to such variations among other species. The normal hepatic arterial pattern was observed in $73.8 \%$, while the anomalous was detected in $26.2 \%$. The CHA originated from the coeliac trunk in 98\%, the RHA originated from the CHA in $86.6 \%$ and the LHA originated from the CHA in 91.2\%. The most common arterial supply of the hepatic segment IV is derived from the LHA (60.2\%). (Folia Morphol 2020; 79, 2: 247-254)

Key word: hepatic artery, anatomical variations, multidetector computed tomography 


\section{INTRODUCTION}

Knowledge of hepatic vasculature variants is mandatory in laparoscopic surgery, liver transplants, radiological abdominal interventions and penetrating abdominal injuries [16]. Lack of familiarity with such variants can result in insufficient management and predispose patients to inadvertent injury during open surgical procedures or percutaneous intervention [7].

Normally (12-49\%), the liver receives its total inflow from the hepatic branch of coeliac trunk [4]. Aberrant hepatic artery refers to a branch that does not arise from coeliac trunk. There are two types of aberrant hepatic artery: accessory and replaced [6]. The accessory hepatic artery is applied when the normal coeliac right hepatic artery (RHA) or left hepatic artery (LHA) is present and there is an additional artery from other sources. The replaced hepatic artery is applied when the normal coeliac RHA or LHA is missing and the replacing artery comes from another source and provides the sole supply to that lobe [6].

Aberrant hepatic arteries can be of major surgical significance in the laparoscopic procedures and operations of gallbladder, liver, upper intestinal tract, and pancreas [19]. Such aberrant arteries can develop a technical problem for infusion treatment and trans-arterial chemoembolisation of neoplasms [19]. Aberrant LHA lies in the hepatogastric ligament and is prone to laceration or ligation causing fatal ischaemic necrosis of left lobe of the liver [1]. In addition, accessory left gastric artery (LGA) arising from aberrant LHA affects the diagnosis and treatment of proximal gastric and distal oesophageal and hand in intra-arterial infusion of chemotherapeutic agents for hepatic neoplasms [17]. Aberrant RHA leads to alteration in the surgical approach and adversely affects the surgical outcome. Injury to aberrant RHA leads to intra- or postoperative bleeding and ischaemia of right lobe of liver [20].

Multi-detector computed tomography (MDCT) angiography is accurate, and reliable in the evaluation of the hepatic artery configuration [22]. It allows faster volume imaging of the whole liver with thinner slices in high spatial resolution within one breath-hold period, when compared with the CT devices with a single detector row [23].

Recognition of the origin of the artery of segment IV is important for donor evaluation for living donor liver transplantation and for the split liver transplantation [12].
We hypothesized that the frequency of normal and aberrant hepatic arteries differs among ethnicities. So, the aim of our work was to study the frequency of normal and aberrant hepatic arteries among Egyptians using MDCT and to compare our prevalence with the prevalence of other nationalities. In addition, the gender differenced were elucidated. Finally, the arterial feeding of hepatic segment IV was determined.

\section{MATERIALS AND METHODS}

The present study was carried out on 500 patients (409 males and 91 females). The mean \pm standard deviation of their ages was $54.06 \pm 11.6$ years. The studied patients were referred to the Radiology Department of Cairo University Hospital and underwent abdominal dynamic enhanced MDCT. The data were obtained during the arterial phase.

Exclusion criteria were impaired renal function (creatinine $>1.2 \mathrm{mg} / \mathrm{dL}$ ), allergy to iodinated contrast media, previous hepatic or major abdominal surgery and all pathological conditions that may modify the vascular anatomy (i.e. parasitic flow in hepatocellular carcinoma) [4].

Permission from the ethics committee was not requested as $C T$ studies followed routine imaging protocols, and written informed consent was obtained from all patients. All procedures were carried out in accordance with the Declaration of Helsinki 1975, revised 2013.

Abdominal CT was performed using two MDCT systems, a 64-row, and a 256-slice system. MDCT coverage extended from the dome of the diaphragm to the inferior margin of the right kidney. Configurations of MDCT system: detector configurations of $64 \times 0.625 \mathrm{~mm}$ or $256 \times 0.5 \mathrm{~mm}$, respectively; section thicknesses of 0.625 or $0.5 \mathrm{~mm}$, respectively; reconstruction intervals of 0.625 or $0.5 \mathrm{~mm}$, respectively; and table speeds of 64 or $256 \mathrm{~mm}$ per rotation, respectively.

Dynamic enhanced MDCT images were obtained in a craniocaudal direction during the hepatic arterial, portal venous and equilibrium phases. A dual-head power injector was used to administer a flush of lopromide (Ultravist; Bayer Schering Pharma, Berlin, Germany) at $370 \mathrm{mg}$ iodine $/ \mathrm{mL}$ and $30 \mathrm{~mL}$ sterile saline $(0.9 \% \mathrm{NaCl})$. The contrast medium and saline solution were injected at $4 \mathrm{~mL} / \mathrm{s}$ through an 18-gauge plastic intravenous catheter placed in an antecubital vein. 
Hepatic arterial phase imaging delays were 11-20 s after descending aorta enhancement to $150 \mathrm{HU}$, as measured by an automatic bolus-tracking technique, and portal venous phase inter-imaging delays were 20-30 s after the aortic enhancement. Equilibrium phase images were acquired $180 \mathrm{~s}$ after completion of the contrast medium administration.

For the purposes of this study, only the data obtained during the arterial phase were downloaded onto an off-line workstation (ADW 4.3; General Electric Healthcare, Milwaukee, WI, USA) for image post-processing and analysis. We used multiplanar reformation in three spatial planes and three-dimensional reformation using volume rendering and maximum intensity projection. Images were reformatted, analysed and assessed with respect to origination sites and the anatomy of the coeliac axis and their major branches. The anatomies of the coeliac trunk and hepatic arterial system were analysed individually, and anatomical variations recorded. We analysed patterns of aortic origin for the four major arteries: LGA, common hepatic artery (CHA), splenic artery and superior mesenteric artery (SMA) with adherence to our modified definition of coeliac axis and Song's definition of CHA, whereby CHA is defined as an arterial trunk containing gastroduodenal artery and at least one segmental hepatic artery, irrespective of its origin and anatomic course [28].

The anatomical variations of hepatic arterial system were defined according to Michel's [28] and Hiatt's classifications [6] (Table 1).

\section{Statistical analysis}

The data obtained from the radiological and anatomical studies were recorded and analysed using IBM SPSS advanced statistics version 21 (SPSS Inc., Chicago, IL). Qualitative data were expressed as frequency and percentage of normal and aberrant hepatic arteries. The gender differences in such variations were clarified using the $\chi^{2}$ test. A p-value $<0.05$ was considered significant.

\section{RESULTS}

According to Michel's classification, the normal anatomy (type I) was observed in 369 (73.8\%) cases, while the anomalous hepatic arterial pattern was detected in 131 (26.2\%) cases. The anomalies were distributed as follows: type II in $36(7.2 \%)$ cases, type III in $60(12 \%)$ cases, types IV and V in 5 cases for each (1\% each), type $\mathrm{VI}$ in $14(2.8 \%)$ cases and
Table 1. Michel's [14] and Hiatt's [6] classifications

\begin{tabular}{lc}
\hline Type & Description \\
\hline Michel's classification & Normal anatomy \\
I & Replaced LHA from LGA \\
III & Replaced RHA from SMA \\
IV & $\begin{array}{c}\text { Replaced RHA and replaced LHA } \\
\text { (types II and III coexist) }\end{array}$ \\
V & Accessory LHA from LGA \\
VI & Accessory RHA from SMA \\
VII & Accessory LHA and accessory RHA \\
VIII & (types V and VI coexist) \\
IX & Replaced RHA and accessory LHA \\
X & or replaced LHA and accessory RHA \\
Hiatt's classification & CHA from SMA \\
I & CHA from LGA \\
II & \\
III & Normal \\
IV & Replaced or accessory RHA + replaced or accessory \\
V & LHA (every combination of a double replaced pattern) \\
VI & CHA from SMA \\
\hline CHA (replaced or accessory) from LGA \\
R
\end{tabular}

CHA — common hepatic artery; LGA - left gastric artery; LHA — left hepatic artery; RHA — right hepatic artery; SMA — superior mesenteric artery

types VIII and IX in a single case for each ( $0.2 \%$ each). Neither type VII nor type X was detected. Nine (1.8\%) unclassified cases were observed (Table 2, Fig. 1).

According to Hiaat's classification, the anomalies were distributed as follows: type II in $41(8.2 \%)$ cases, type III in $74(14.8 \%)$ cases, type IV in $6(1.2 \%)$ cases, type $\mathrm{V}$ in a single (0.2\%) case and type $\mathrm{VI}$ in $2(0.4 \%)$ cases. Finally, $7(1.4 \%)$ unclassified cases were observed (Table 2).

According to Michel's classification, the unclassified cases were CHA from the aorta, the CHA from the superior mesenteric with the LHA from the coeliac trunk, the RHA from the aorta, the accessory right hepatic from the aorta, absent coeliac trunk (Fig. 2).

The anatomical variation of the origin of the $\mathrm{CHA}$ showed normal origin from the coeliac trunk in $98 \%$ ( $79.8 \%$ males and $18.2 \%$ females). It originated from the abdominal aorta in $0.4 \%$ and from the SMA in $0.4 \%$. It was absent in $1.2 \%$ of the cases. The anatomical variation of the origin of the RHA was normal origin from $\mathrm{CHA}$ in $86.6 \%$ (69.8\% were males and 
Table 2. Frequency of distribution of hepatic artery

\begin{tabular}{lcc}
\hline Type & Frequency & Per cent \\
\hline Michel's classification & & \\
I & 369 & 73.8 \\
II & 36 & 7.2 \\
III & 60 & 12.0 \\
IV & 5 & 1.0 \\
V & 5 & 1.0 \\
VI & 14 & 2.8 \\
VII & 0 & 0 \\
VIII & 1 & 0.2 \\
IX & 1 & 0.2 \\
X & 0 & 0 \\
Others & 9 & 1.8 \\
Hiaat's classification & & \\
I & 369 & 73.8 \\
II & 41 & 8.2 \\
III & 74 & 14.8 \\
IV & 6 & 1.2 \\
V & 1 & 0.2 \\
VI & 2 & 0.4 \\
Others & 7 & 1.4 \\
Total & 500 & 100 \\
\hline
\end{tabular}

$16.8 \%$ were females), while it originated from SMA in $13.2 \%$ ( $11.8 \%$ were males and $1.4 \%$ were females) and from abdominal aorta in $0.2 \%$ (a single male case). The anatomical variation of the origin of the LHA was the normal origin from the CHA in $91.2 \%$, while it originated from the LGA in $8.8 \%$ (Table 3 , Figs. 1, 2).

The most common arterial supply of the hepatic segment IV is derived from the LHA (60.2\%), followed by the RHA in 35\%. Less commonly, blood supply derived from hepatic artery proper (HAP) in $1 \%$. Combined blood supply derived from the LHA and RHA in $0.8 \%$, from the LHA and HAP in $2 \%$ and the least encountered was from the RHA and HAP in $0.4 \%$ (Table 4 ).

\section{DISCUSSION}

A comparison with other angiographic studies based on Michel's classification [3, 4, 10, 14, 19, 21, $22,26]$ and Hiatt's classification $[6,9,10,15,18$, $25,29]$ was exhibited in Table 5 . Our study showed a higher percentage of normal hepatic artery anatomy (73.8\%) compared to that of Michel's study (55\%) [28]. Most of the radiological investigations displayed percentages near to that found in our study. The

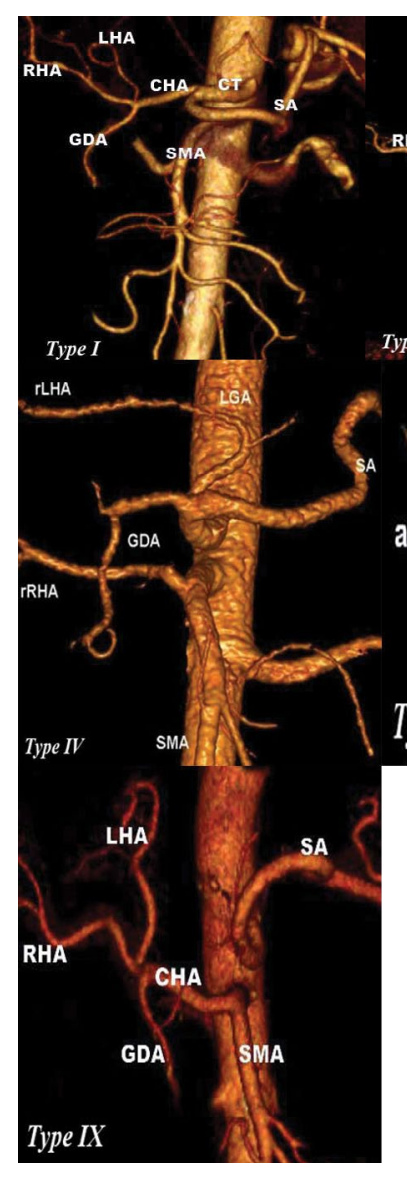

Figure 1. Multi-detector computed tomography angiography images showing Michel's type I configuration (normal anatomy), Michel's type II configuration (replaced LHA from LGA), Michel's type III configuration (replaced RHA from SMA), Michel's type IV configuration (replaced LHA from LGA and replaced RHA from SMA), Michel's type VI configuration (accessory RHA from SMA), Michel's type VIII configuration (accessory LHA from LGA and replaced RHA from SMA), Michel's type IX configuration (CHA from SMA); CHA - common hepatic artery; LGA — left gastric artery; LHA — left hepatic artery; RHA — right hepatic artery; SMA — superior mesenteric artery. 


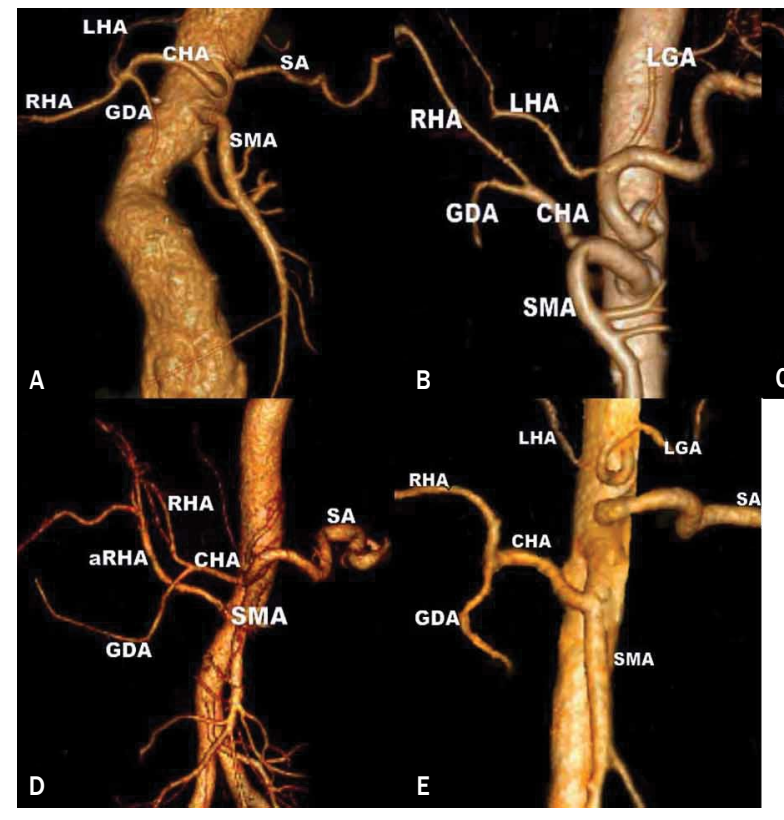

Table 3. Frequency of origin of the right hepatic artery (RHA) and left hepatic artery (LHA)

\begin{tabular}{|c|c|c|c|c|c|}
\hline \multirow[t]{2}{*}{ Gender } & & \multicolumn{3}{|c|}{ Origin of the RHA } & \multirow[t]{2}{*}{$\mathbf{P}$} \\
\hline & & CHA & SMA & $\mathbf{A A}$ & \\
\hline \multirow[t]{3}{*}{ Male } & Count & 349 & 59 & 1 & $0.2^{*}$ \\
\hline & Within RHA & $80.6 \%$ & $89.4 \%$ & $100.0 \%$ & \\
\hline & Total & $69.8 \%$ & $11.8 \%$ & $0.2 \%$ & \\
\hline \multirow[t]{3}{*}{ Female } & Count & 84 & 7 & 0 & \\
\hline & Within RHA & $19.4 \%$ & $10.6 \%$ & $0.0 \%$ & \\
\hline & Total & $16.8 \%$ & $1.4 \%$ & $0.0 \%$ & \\
\hline \multirow[t]{3}{*}{ Total } & Count & 433 & 66 & 1 & \\
\hline & Within RHA & $100.0 \%$ & $100.0 \%$ & $100.0 \%$ & \\
\hline & Total & $86.6 \%$ & $13.2 \%$ & $0.2 \%$ & \\
\hline \multirow[t]{2}{*}{ Gender } & & \multicolumn{3}{|c|}{ Origin of the LHA } & $\mathbf{P}$ \\
\hline & & CHA & & LGA & \\
\hline \multirow[t]{3}{*}{ Male } & Count & 374 & & 35 & $0.3^{*}$ \\
\hline & Within LHA & $82.0 \%$ & & $79.5 \%$ & \\
\hline & Total & $74.8 \%$ & & $7.0 \%$ & \\
\hline \multirow[t]{3}{*}{ Female } & Count & 82 & & 9 & \\
\hline & Within LHA & $18.0 \%$ & & $20.5 \%$ & \\
\hline & Total & $16.4 \%$ & & $1.8 \%$ & \\
\hline \multirow[t]{3}{*}{ Total } & Count & 456 & & 44 & \\
\hline & Within LHA & $100.0 \%$ & & $100.0 \%$ & \\
\hline & Total & $91.2 \%$ & & $8.8 \%$ & \\
\hline
\end{tabular}

${ }^{*}$ Statistically insignificant using the Chi-square tests; $\mathrm{AA}$ — abdominal aorta; $\mathrm{CHA}$ common hepatic artery; LGA — left gastric artery; SMA — superior mesenteric artery

anatomical variations in our study were low (26.2\%) compared to the variations reported by Michel's
Table 4. Frequency of arterial supply of segment IV

\begin{tabular}{lcc}
\hline Arterial supply of segment IV & Frequency & Per cent \\
\hline LHA & 304 & $60.8 \%$ \\
RHA & 175 & $35 \%$ \\
HAP & 5 & $1 \%$ \\
LHA+RHA & 4 & $0.8 \%$ \\
LHA+HAP & 10 & $2 \%$ \\
RHA+HAP & 2 & $0.4 \%$ \\
LHA+RHA+HAP & 0 & $0 \%$ \\
\hline
\end{tabular}

LHA — left hepatic artery; RHA — right hepatic artery; HAP — hepatic artery proper

(45\%), Saba's (38.63\%) and De Cecco's (34\%) [4, $22,28]$. Many researchers exhibited percentages like that found in our study (Table 5).

The most common anatomical variants observed in our study was the replaced RHA arising from SMA (Michel's type III). It constituted $12 \%$ of our studied cases which was in accordance with the findings of Michel (11\%), Rygaard (13.4\%), De Cecco et al. (9.2\%), Saba and Mallarini (10.56\%) [4, 21, 22, 28]. A low percentage of this variation was found in the studies of Daly et al. (6\%) [3], Chen et al. (5.2\%) [2], Stemmler et al. (6.3\%) [26]. The replaced RHA is a beneficial variant in right hepatic lobe living donors transplant, as the common postoperative complication in liver transplantation is hepatic artery thrombosis because of shorter and thinner hepatic artery graft. However, the replaced RHA in such cases provides a longer and larger graft, thus reducing chances of hepatic artery thrombosis [13]. 
Table 5. Comparison with other angiographic studies based on Michel's and Hiatt's classification

\begin{tabular}{|c|c|c|c|c|c|c|c|c|c|c|}
\hline & Type & $\begin{array}{l}\text { Current } \\
\text { series }\end{array}$ & $\begin{array}{l}\text { Michel's, } \\
1966 \text { [14] }\end{array}$ & $\begin{array}{l}\text { Koops et al., } \\
2004 \text { [10] }\end{array}$ & $\begin{array}{l}\text { Saba and } \\
\text { Mallarini, } \\
2011 \text { [22] }\end{array}$ & $\begin{array}{l}\text { De Cecco et al., } \\
2009 \text { [4] }\end{array}$ & $\begin{array}{c}\text {, Stemmler et al., } \\
2004 \text { [26] }\end{array}$ & $\begin{array}{l}\text { Chen et al., } \\
1998 \text { [2] }\end{array}$ & $\begin{array}{l}\text { Daly et al., } \\
1984 \text { [3] }\end{array}$ & $\begin{array}{l}\text { Rygaard et al., } \\
1986 \text { [21] }\end{array}$ \\
\hline \multirow{13}{*}{$\begin{array}{l}\text { Comparison } \\
\text { based on } \\
\text { Michel's } \\
\text { classifica- } \\
\text { tion }\end{array}$} & 1 & 73.8 & 55 & 79.1 & 61.37 & 66 & 80.9 & 80.3 & 76 & 75.5 \\
\hline & $\|$ & 7.2 & 10 & 2.5 & 7.48 & 5.2 & 0 & 7.8 & 4 & 4.6 \\
\hline & III & 12.0 & 11 & 8.6 & 10.56 & 9.2 & 6.3 & 5.2 & 6 & 13.4 \\
\hline & IV & 1.0 & 1 & 1 & 1.35 & 2 & 0 & 0.7 & 0 & 0.9 \\
\hline & V & 1.0 & 8 & 0.5 & 6.69 & 5.2 & 7.9 & 1.3 & 3.5 & 0 \\
\hline & $\mathrm{VI}$ & 2.8 & 7 & 3.3 & 6.99 & 4 & 0 & 1.5 & 4 & 0 \\
\hline & VII & 0 & 1 & 0.2 & 0.73 & 2 & 1.6 & 0.5 & 0 & 0.5 \\
\hline & VIII & 0.2 & 2 & 0.2 & 1.9 & 0.6 & 1.6 & 0 & 0 & 0.5 \\
\hline & IX & 0.2 & 4.5 & 2.8 & 1.59 & 2 & 1.6 & 1.6 & 2 & 1.4 \\
\hline & $x$ & 0 & 0.5 & 0 & 0.31 & 0 & 0 & 0 & 0 & 0 \\
\hline & Others & 1.8 & 0 & 1.8 & .09 & 3.3 & 0 & 1.1 & 6 & 0 \\
\hline & Total [\%] & 100 & 100 & 100 & 100 & 100 & 100 & 100 & 100 & 100 \\
\hline & Type & $\begin{array}{l}\text { Current } \\
\text { study }\end{array}$ & $\begin{array}{l}\text { Hiatt et al., } \\
1994 \text { [6] }\end{array}$ & $\begin{array}{l}\text { Niederhuber } \\
\text { and } \\
\text { Ensminger, } \\
1983 \text { [18] }\end{array}$ & $\begin{array}{c}\text { Kemeny et al., } \\
1986 \text { [9] }\end{array}$ & $\begin{array}{c}\text { Koops et al., } \\
2004 \text { [10] }\end{array}$ & $\begin{array}{l}\text { Toda et al., } \\
1987 \text { [29] }\end{array}$ & $\begin{array}{l}\text { Mortelé et al., } \\
2003 \text { [15] }\end{array}$ & $\begin{array}{l}\text { Soin et al., } \\
1996 \text { [25] }\end{array}$ & \\
\hline \multirow{8}{*}{$\begin{array}{l}\text { Compari- } \\
\text { son based } \\
\text { on Hiatt's } \\
\text { classifica- } \\
\text { tion }\end{array}$} & 1 & 73.8 & 75.7 & 73 & 59 & 79.1 & 64.5 & 76 & 69.4 & \\
\hline & $\|$ & 8.2 & 9.7 & 10 & 17 & 3 & 12.8 & 7 & 14.2 & \\
\hline & III & 14.8 & 10.6 & 11 & 18 & 11.9 & 9.9 & 7 & 8.7 & \\
\hline & IV & 1.2 & 2.3 & 2 & 2 & 1.3 & 3.2 & 3 & 2.7 & \\
\hline & V & 0.2 & 1.5 & 0 & 3 & 2.8 & 5 & 3 & 2.3 & \\
\hline & $\mathrm{VI}$ & 0.4 & 0.2 & 0 & 0 & 0.2 & 0 & 0 & 0.2 & \\
\hline & Others & 1.4 & 0 & 5 & 1 & 1.7 & 4.1 & 4 & 2.5 & \\
\hline & Total [\%] & 100 & 100 & 100 & 100 & 100 & 100 & 100 & 100 & \\
\hline
\end{tabular}

The second most frequent variation in our study was the replaced LHA arising from the LGA (Michel's type II). It constituted $7.2 \%$ of the studied cases which was in accordance with the findings of Michel (10\%) [22], Chen et al. (7.8\%) [2], Saba and Mallarini (7.48\%) [22]. A low percentage of this variation was found in the studies of Daly et al., 1984 (6\%) [3], Rygaard et al., 1986 (4.6\%) [21], De Cecco et al., 2009 (5.2\%) [4], Koops et al., 2004 (2.5\%) [10]. Stemmler et al., 2004 [26] reported absence of such variant in their study. Type II and III variants are suitable for the operation, owing to the longer replaced right or left hepatic arteries allowing the surgeon to perform safer anastomosis [17].

The existence of replaced RHA and LHA (Michel's type IV) constituted about (1\%) of the studied cases. Most of the radiological investigations displayed percentages like that. Rygaard et al. [21] and Stemmler et al. [26] reported absence of such variant in their studies.
Great difference was observed in the number of accessory hepatic arteries detected (Michel's types $\mathrm{V}$ and $\mathrm{VI}$ ), with low prevalence in most studies including our study. This difference might be due to the small size of the accessory branches, resulting in the general underestimation of these arteries on angiography [10]. Rygaard et al. [21] reported absence of such variants in their study.

The prevalence of the rare unclassified Michel's or Hiatt's anomalies in our study does not differ from those reported in other publications. We observed five variants that are not included in Michel's scheme; CHA from aorta, CHA from superior mesenteric and left hepatic from coeliac trunk, RHA from aorta, accessory right hepatic from aorta, absent coeliac trunk.

Common hepatic artery originated directly from the abdominal aorta in $0.4 \%$ of the studied cases. Chen et al., 1998 [2] and Sureka et al., 2013 [27] reported such variant in $0.5 \%$ and $0.33 \%$, respectively. 
Other researchers found a higher percentage in their studies $(1.7 \%, 1.35 \%$, respectively) $[5,24]$. Right and left hepatic arteries originated from the coeliac trunk directly in $0.2 \%$ of our cases. Sureka et al., 2013 [27] reported a higher incidence (1\%). Right hepatic artery originated directly from the aorta in $0.2 \%$ of our cases. lezzi et al., 2008 [8], Ugurel et al., 2010 [30] and Sureka et al., 2013 [27] reported variable percentage of this variant $(0.2 \%, 0.3 \%, 1 \%)$.

Recognition of the origin of the artery of segment IV is important for donor evaluation for living donor liver transplantation and for the split liver transplantation [12]. Left hepatic artery feeding segment IV occurred in $60.2 \%$ of our cases vs. $53 \%$ of Lee's and $55.1 \%$ in Saba's studies. Right hepatic artery feeding segment IV occurred in $35 \%$ of our studied cases vs. $39 \%$ of Lee's and (31.25\%) in Saba's studies. Finally, double blood supply from left and right hepatic arteries was found in $0.8 \%$ while it was $2 \%$ in Lee's and $6.3 \%$ in Saba's studies [11, 22]. The latter authors also reported triple blood supply from CHA, LHA, and RHA in $0.6 \%$ which was not found in our study. If segment IV artery originates from the RHA, the RHA should be clamped after it gives off the segment IV artery [15]. In right lobe transplantation, if the right hepatic arterial origin of the segment IV artery is not detected prior to the surgery and the RHA is clamped as it takes off from the HAP, the left lobe medial segment that remains in the donor will develop ischaemia [15].

\section{CONCLUSIONS}

In conclusion, hepatic artery variations among Egyptians have a different distribution when compared to such variations among other species. The normal hepatic arterial pattern was observed in $73.8 \%$, while the anomalous one was detected in $26.2 \%$. The CHA originated from the coeliac trunk in $98 \%$, the RHA originated from the CHA in $86.6 \%$ and the LHA originated from the CHA in $91.2 \%$. The most common arterial supply of the hepatic segment IV is derived from the LHA (60.2\%).

\section{REFERENCES}

1. Abid B, Douard R, Chevallier JM, et al. [Left hepatic artery: anatomical variations and clinical implications]. Morphologie. 2008; 92(299): 154-161, doi: 10.1016/j. morpho.2008.10.001, indexed in Pubmed: 19008142.

2. Chen CC, Lee RC, Tseng HS, et al. Normal and variant anatomy of hepatic arteries: angiographic experience. Zhonghua Yi Xue Za Zhi (Taipei. 1998; 61(1): 17-23.
3. Daly JM, Kemeny N, Oderman P, et al. Long-term hepatic arterial infusion chemotherapy. Anatomic considerations, operative technique, and treatment morbidity. Arch Surg. 1984; 119(8): 936-941, doi: 10.1001/archsurg.1984.01390200054013, indexed in Pubmed: 6378147.

4. De Cecco CN, Ferrari R, Rengo M, et al. Anatomic variations of the hepatic arteries in 250 patients studied with 64-row CT angiography. Eur Radiol. 2009; 19(11): 2765-2770, doi: 10.1007/s00330-009-1458-7, indexed in Pubmed: 19471940.

5. Ferrari R, De Cecco CN, Jafrate F, et al. Anatomical variations of the coeliac trunk and the mesenteric arteries evaluated with 64-row CT angiography. Radiol Med. 2007; 112(7): 988-998.

6. Hiatt JR, Gabbay J, Busuttil RW. Surgical anatomy of the hepatic arteries in 1000 cases. Ann Surg. 1994; 220(1): 50-52, doi: 10.1097/00000658-199407000-00008, indexed in Pubmed: 8024358.

7. Ibrahim AS, Khaled HM, Mikhail NN, et al. Cancer incidence in Egypt: results of the national population-based cancer registry program. J Cancer Epidemiol. 2014: 437971.

8. lezzi RR, Cotroneo AR, Filippone A, et al. Multidetector-row computed tomography angiography in abdominal aortic aneurysm treated with endovascular repair: evaluation of optimal timing of delayed phase imaging for the detection of low-flow endoleaks. J Comput Assist Tomogr. 2008; 32(4): 609-615.

9. Kemeny MM, Hogan JM, Goldberg DA, et al. Continuous hepatic artery infusion with an implantable pump: problems with hepatic artery anomalies. Surgery. 1986; 99(4): 501-504.

10. Koops A, Wojciechowski B, Broering DC, et al. Anatomic variations of the hepatic arteries in 604 selective celiac and superior mesenteric angiographies. Surg Radiol Anat. 2004; 26(3): 239-244, doi: 10.1007/s00276-004-0229-z, indexed in Pubmed: 14968265.

11. Lee SS, Kim TK, Byun JH, et al. Hepatic arteries in potential donors for living related liver transplantation: evaluation with multi-detector row CT angiography. Radiology. 2003; 227(2): 391-399.

12. Lo CM, Fan ST, Liu CL, et al. Adult-to-Adult Living Donor Liver Transplantation Using Extended Right Lobe Grafts. Ann Surg. 1997; 226(3): 261-270, doi: 10.1097/00000658199709000-00005.

13. Marcos A, Killackey M, Orloff MS, et al. Hepatic arterial reconstruction in 95 adult right lobe living donor liver transplants: evolution of anastomotic technique. Liver Transpl. 2003; 9(6): 570-574, doi: 10.1053/jlts.2003.50093, indexed in Pubmed: 12783397.

14. Michels AA. Newer anatomy of the liver and its variant blood supply and collateral circulation. Am J Surg. 1966; 112(3): 337-347.

15. Mortelé KJ, Cantisani V, Troisi R, et al. Preoperative liver donor evaluation: Imaging and pitfalls. Liver Transpl. 2003; 9(9): S6-14, doi: 10.1053/jlts.2003.50199, indexed in Pubmed: 12942472.

16. Munshi IA, Fusco D, Tashjian D, et al. Occlusion of an aberrant right hepatic artery, originating from the superior mesenteric artery, secondary to blunt trauma. J Trauma. 2000; 48(2): 325-326, doi: 10.1097/00005373200002000-00025, indexed in Pubmed: 10697098. 
17. Nakamura T, Tanaka K, Kiuchi T, et al. Anatomical variations and surgical strategies in right lobe living donor liver transplantation: lessons from 120 cases. Transplantation. 2002; 73(12): 1896-1903.

18. Niederhuber JE, Ensminger WD. Surgical considerations in the management of hepatic neoplasia. Semin Oncol. 1983; 10(2): 135-147.

19. Németh $K$, Deshpande R, Máthé $Z$, et al. Extrahepatic arteries of the human liver - anatomical variants and surgical relevancies. Transplant International. 2015; 28(10): 1216-1226.

20. Rammohan A, Palaniappan R, Pitchaimuthu A, et al. Implications of the presence of an aberrant right hepatic artery in patients undergoing pancreaticoduodenectomy. World J Gastrointest Surg. 2014; 6(1): 9-13, doi: 10.4240/ wjgs.v6.i1.9, indexed in Pubmed: 24627736.

21. Rygaard $H$, Forrest $M$, Mygind T. Anatomic variants of the hepatic arteries. Acta Radiol Diagn (Stockh). 1986; 27(4): 425-427.

22. Saba L, Mallarini G. Anatomic variations of arterial liver vascularization: an analysis by using MDCTA. Surg Radiol Anat. 2011; 33(7): 559-568, doi: 10.1007/s00276-0110778-x, indexed in Pubmed: 21249363.

23. Saylisoy S, Atasoy C, Ersöz S, et al. Multislice CT angiography in the evaluation of hepatic vascular anatomy in potential right lobe donors. Diagn Interv Radiol. 2005; 11(1): 51-59.

24. Selvaraj L, Sundaramurthi I. Study of normal branching pattern of the coeliac trunk and its variations using CT angiography. J Clin Diagn Res. 2015; 9(9): AC01-AC04, doi: $10.7860 / J C D R / 2015 / 12593.6523$, indexed in Pubmed: 26500893.

25. Soin AS, Friend PJ, Rasmussen A, et al. Donor arterial variations in liver transplantation: management and outcome of 527 consecutive grafts. Br J Surg. 1996; 83(5): 637-641.

26. Stemmler BJ, Paulson EK, Thornton FJ, et al. Dual-phase 3D MDCT angiography for evaluation of the liver before hepatic resection. AJR Am J Roentgenol. 2004; 183(6): 1551-1557.

27. Sureka B, Mittal MK, Mittal A, et al. Variations of celiac axis, common hepatic artery and its branches in 600 patients. Indian J Radiol Imaging. 2013; 23(3): 223-233, doi: 10.4103/0971-3026.120273, indexed in Pubmed: 24347852.

28. Thangarajah A, Parthasarathy R. Celiac Axis, Common Hepatic and Hepatic Artery Variants as Evidenced on MDCT Angiography in South Indian Population. J Clin Diagn Res. 2016; 10(1): TC01-TC05, doi: 10.7860/ JCDR/2016/17045.7105, indexed in Pubmed: 26894140.

29. Toda S, Makowka L, Tzakis AG, et al. Hepatic artery in liver transplantation. Transplant Proc. 1987; 19(1 Pt 3): 2406-2411.

30. Ugurel MS, Battal B, Bozlar U, et al. Anatomical variations of hepatic arterial system, coeliac trunk and renal arteries: an analysis with multidetector $\mathrm{CT}$ angiography. $\mathrm{Br} \mathrm{J}$ Radiol. 2010; 83(992): 661-667, doi: 10.1259/bjr/21236482, indexed in Pubmed: 20551256. 